\title{
A EDUCAÇÃO INFANTIL EM FOCO: DESAFIOS E PERSPECTIVAS PARA A EDUCAÇÃO DOS BEBÊS
}

\author{
LA EDUCACIÓN INFANTIL EN DESTAQUE: RETOS Y PERSPECTIVAS PARA \\ LA EDUCACIÓN DE LOS BEBÉS
}

\section{CHILDHOOD EDUCATION IN FOCUS: CHALLENGES AND PERSPECTIVES FOR THE EDUCATION OF BABIES}

\author{
Jaqueline Delgado PASCHOAL ${ }^{1}$ \\ Gilmara Lupion MORENO ${ }^{2}$ \\ Marta Regina Furlan de OLIVEIRA ${ }^{3}$ \\ Marta Silene de BARROS ${ }^{4}$
}

RESUMO: O artigo discute o trabalho pedagógico nas escolas infantis, a partir das concepções de professoras que atuam no berçário. $O$ objetivo se justifica por problematizar o descompasso existente entre o que pensam e o que fazem essas profissionais, já que, na prática, os cuidados relacionados ao corpo da criança acontecem de maneira mecânica e dissociada de um trabalho intencionalmente educativo. Para se verificar como essa questão é entendida pelas professoras, foi aplicado um questionário com questões abertas que buscou levantar aspectos da organização do trabalho pedagógico com bebês. Os resultados indicam que, do ponto de vista prático, ainda há equívocos bastante significativos na atuação dessas profissionais, já que a preocupação é somente com a higiene e com a segurança física dos bebês. Assim, é necessário que sejam pensadas ações pedagógicas, para o berçário, que considerem o ensino como possibilidade educativa no trabalho com os bebês, visando ao seu aprendizado e ao desenvolvimento integral.

PALAVRAS-CHAVE: Educação. Concepções. Práticas. Professoras. Crianças.

RESUMEN: El artículo discute el trabajo pedagógico en las escuelas infantiles, a partir de las concepciones de profesoras que actúan en la guardería infantil. El objetivo se justifica por problematizar el descompás existente entre lo que piensan y lo que hacen esas profesionales, una vez que, en la práctica, los cuidados relacionados al cuerpo del niño ocurren de manera mecánica y disociada de un trabajo intencionalmente educativo. Para comprobarse como las profesoras comprenden esa cuestión, se realizó una encuesta con cuestiones abiertas que buscó identificar aspectos de la organización del trabajo pedagógico con bebés. Los resultados indican que, desde el punto de vista práctico, hay, aún, equívocos muy significativos en la actuación de esas profesionales, pues la preocupación es solamente con la higiene y con la seguridad física de los niños. Así, se hace necesario pensar en acciones pedagógicas,

\footnotetext{
${ }^{1}$ Pós Doutora em Educação pela Universidade Paulista Julio Mesquita- Assis Docente do Departamento de Educação da Universidade Estadual de Londrina

${ }^{2}$ Doutora em Educação. Docente no Departamento de Educação da Universidade Estadual de Londrina

3 Pós Doutora em Educação pela Universidade Paulista Julio de Mesquita- Marilia. Docente no Departamento de Educação da Universidade Estadual de Londrina

${ }^{4}$ Universidade Estadual de Londrina
} 
para la guardería, que consideren la enseñanza como posibilidad educativa en el trabajo con los niños de corta edad, con enfoque en su aprendizaje y su desarrollo integral.

PALABRAS CLAVE: Educación. Concepciones. Prácticas. Profesores. Niños.

ABSTRACT: The article discuss the pedagogical work in children's schools, from the conceptions of teachers who work in the nursery. The intent of this research is justified by questioning the existing gap between what they think and what they do these professionals, since in practice the care related to the child's body happen mechanical and dissociated way of an intentionally educational work. To see how this issue is perceived by teachers, a questionnaire with open questions that sought to raise aspects of the pedagogical work organization babies was applied. The survey results indicate that, from a practical point of view, there are still quite significant mistakes in the work of these professionals, since the concern is only with the hygiene and the physical safety of babies. Thus, it is necessary that educational activities are designed for the nursery, to consider teaching as an educational opportunity in working with babies, aimed at their learning and integral development.

KEYWORDS: Education. Concepts. Practices. Teachers. Children.

\section{Primeiras considerações}

A criança, desde que nasce, forma, para si, capacidades, habilidades e aptidões humanas, principalmente por meio das interações sociais, que contribuem para o seu processo de educação, segundo Leontiev (1988). Para Vygotsky (2003), é nessa fase da vida que ela começa a se apropriar das objetivações humanas em sua relação com o adulto, sobretudo, porque seu desenvolvimento intelectual depende das relações que estabelece com o outro, bem como, com os fatores sociais. Na realidade, o processo de formação e conhecimento está estreitamente ligado às experiências culturais vividas pela criança na interação com os mais experientes, o que possibilita a internalização de novos conhecimentos.

É nesse processo que a criança aprende com o outro e se desenvolve, uma vez que as qualidades humanas apreendidas desde que nasce são vividas, primeiramente, no âmbito social, na coletividade, segundo Vygotsky (1997). Essas qualidades estão presentes nos valores, nas crenças, na linguagem, no modo de ver, sentir, pensar e agir e nos instrumentos materiais e imateriais, e toda esta materialidade é internalizada pelas crianças desde que nascem, ao fazerem uso dos elementos objetivados pela cultura humana, que representam, de alguma forma, as situações que compartilham. 
Daí a importância de um atendimento de qualidade nas instituições destinadas à primeira infância, visto que a função precípua desses espaços é promover o desenvolvimento integral de todas as crianças, independentemente da classe social de origem. Por esse motivo, esta pesquisa se justifica por apontar para as inúmeras possibilidades de um trabalho mais inovador, que respeite os direitos e as necessidades infantis em sua plenitude, pois se verifica que, na prática, ainda há uma dicotomia entre os cuidados e a educação, visto que o trabalho das professoras ${ }^{5}$ se resume a ações relacionadas à higiene do corpo dos bebês, em detrimento de um trabalho intencionalmente pedagógico.

Desse modo, com o propósito de conhecer o que pensam e o que fazem as professoras responsáveis pelo trabalho com os pequenos, elegeu-se um primeiro questionamento que norteou as reflexões deste estudo: "Do ponto de vista teórico e metodológico, quais são as concepções e as práticas das professoras na organização do trabalho pedagógico no berçário?”. Para Pádua (2004, p. 44), “[...] a formulação e a descrição do problema da pesquisa não são estabelecidas de forma mecânica ou inquestionável e podem sofrer alterações à medida que se avança no processo do estudo". Desta maneira, outros elementos se agregam ao questionamento inicial, tais como: “É possível ensinar no berçário?”; “Os bebês são atendidos em suas necessidades básicas, como na troca de fralda, hora do descanso, banho, alimentação, controle dos esfíncteres e atividades orientadas?"; "O aspecto educativo se faz presente, efetivamente, nesses momentos?"; “As brincadeiras são incorporadas como metodologia de trabalho?”; "Quais são as maiores dificuldades encontradas no cotidiano do trabalho com os bebês?".

Para responder às inúmeras indagações, o estudo buscou conhecer a percepção das professoras sobre o trabalho pedagógico desenvolvido no berçário e apontar os desafios e as perspectivas de um trabalho de qualidade que reconheça as especificidades desse nível de ensino, sobretudo no que tange à integração entre cuidados e educação no cotidiano dessas instituições. Participaram da pesquisa um total de dezoito professoras, provenientes de escolas infantis particulares e públicas, do município de Londrina-Pr. Para a coleta de dados, foi aplicado um questionário que envolveu questões relacionadas às finalidades da educação infantil; à indissociabilidade entre cuidados, educação e ensino no berçário; à relevância das brincadeiras na organização do trabalho pedagógico

${ }^{5}$ Utiliza-se a palavra no feminino devido ao fato de que as mulheres constituem a grande maioria, dos docentes, nessa etapa educacional. 
das professoras; às dificuldades encontradas no desenvolvimento da rotina; e à participação das famílias no cotidiano das instituições.

Assim, a partir das concepções das professoras, atreladas ao estudo crítico e comprometido do que deva, realmente, ser o espaço de ensino e cuidado no berçário, acredita-se que é possível pensar em novos horizontes pedagógicos voltados ao trabalho com a criança pequena. Para isso, as reflexões deste estudo foram divididas em dois momentos: no primeiro, traçou-se um panorama geral sobre a relevância da educação infantil como espaço de promoção de aprendizagem da criança e sobre os desafios a partir dos avanços e descompassos das determinações legais que tratam desse nível de ensino; no segundo momento, foram apresentados os resultados da pesquisa empírica sobre as percepções das professoras acerca do trabalho pedagógico com os bebês.

\section{A educação infantil como direito da criança}

A revisão do papel das escolas infantis, em meados da década de 1980, por diferentes setores da sociedade, sinalizava a importância dessas instituições para além de um espaço de cuidados e guarda das crianças, enquanto as mães trabalhavam fora. A superação da assistência e a compensação para a criação de espaços de promoção da aprendizagem e desenvolvimento das crianças, por meio da interação com os pares, possibilitaram a substituição da função compensatória, defendida pelo discurso oficial, pela função educativa (KRAMER, 1995).

$\mathrm{Na}$ realidade, o ponto de partida da superação de uma educação que entendia as crianças como pobres, "[...] carentes, deficientes e inferiores na medida em que não correspondem ao padrão estabelecido" (KRAMER, 1995, p. 24), para uma educação que passou a perceber a criança como "[...] sujeito histórico e de direitos que, nas interações, relações e práticas cotidianas que vivencia, constrói sua identidade pessoal e coletiva” (BRASIL, 2010, p. 12), foi a promulgação da Constituição Federal de 1988. Essa nova lei reconhece a criança como sujeito de direitos, inclusive, o direito à educação desde o nascimento, ao determinar o dever do Estado de garantir creches e pré-escolas às crianças de zero a cinco ${ }^{6}$ anos de idade.

Tal fato possibilitou o reconhecimento da educação infantil como parte da educação básica na Lei de Diretrizes e Bases da Educação Nacional de 1996, que, ao tratar da composição dos níveis escolares, inseriu essa etapa educacional nos sistemas

${ }^{6}$ Idade alterada de seis para cinco anos de idade pela Emenda Constitucional no ${ }^{53}$, de 2006. 
de ensino. Essas instituições que, até então, se vinculavam à área de assistência social, passaram a ser de responsabilidade da educação, e sua função pedagógica e não mais assistencial se tornou condição primordial para do desenvolvimento integral da criança em todos os aspectos: físico, psicológico, intelectual e social, em complementação à ação da família e da comunidade (BRASIL, 1996).

Ao reiterar as orientações das políticas para a infância, a Resolução nº 5, de 17 de dezembro de 2009, que fixa as Diretrizes Curriculares Nacionais para a educação infantil, determina que o projeto pedagógico deve orientar todas as ações da instituição, sobretudo no que diz respeito à aprendizagem e ao desenvolvimento das crianças que serão educadas e cuidadas. O currículo, nesse sentido, deve ser entendido como "um conjunto de práticas que buscam articular as experiências e os saberes das crianças com os conhecimentos que fazem parte do patrimônio cultural, artístico, ambiental, científico e tecnológico", de modo a promover seu desenvolvimento pleno (BRASIL, 2009, p.12).

Ainda que tenha se tornado exigência legal, $\operatorname{Kramer}(2002$, p.12) esclarece que o projeto pedagógico não pode perder sua essência, já que o trabalho coletivo "[...] é o ponto de partida e de chegada na elaboração e na implementação de projetos, o direito à voz e à criação precisa ser garantido". Isso quer dizer que professores e crianças precisam ser respeitados como sujeitos da história, mas, também, em suas singularidades. Segundo Kramer:

\footnotetext{
Como professores e professoras, precisamos conhecer as crianças e os professores (nossos colegas) dos diferentes contextos que trabalhamos. Eles e elas são sujeitos sociais, têm o direito a experiências de cultura, brincadeiras, literatura, cinema, museus, música, pintura e à arte em geral (KRAMER, 2002, p. 13).
}

As práticas de cuidado e de educação devem permear as ações no trato com as crianças, assim como a circulação de saberes, no entanto, é preciso condições adequadas de trabalho, haja vista que "[...] em condições precárias, não se educa, nem se ensina, nem se cuida" (KRAMER, 2002, p. 13). Isso significa que o poder público precisa prover recursos e condições de trabalho afim de assegurar um atendimento de qualidade para as crianças e suas famílias, mas, também, para seus profissionais.

A garantia desses direitos, frente às proposições das leis, torna-se um desafio à medida que a Emenda Constitucional no 59/2009 tornou o ensino obrigatório dos quatro aos dezessete anos de idade, a partir de 2016, excluindo a faixa etária de zero a três anos de idade. Isso porque a Lei ${ }^{\circ}$ 12.796, de 04 de abril de 2013, altera a Lei de Diretrizes e 
Bases (1996), ao determinar, em seu artigo $4^{\circ}$, inciso I, que a educação básica obrigatória e gratuita ocorrerá a partir dos quatro anos e se estenderá até os dezessete anos de idade, compreendendo a pré-escola, o ensino fundamental e o ensino médio.

Do ponto de vista legal, o paradoxo se encontra na existência de “[...] duas medidas legais diferentes para uma mesma etapa de educação que dividem a etapa em duas, recuperando, de certa maneira, sua divisão histórica" (NASCIMENTO, 2011, p. 155). A referida Emenda contradiz, também, a Lei 11.114/05, que altera o artigo 30 da LDB de 1996, ao dividir a educação infantil em creches e pré-escolas apenas no que tange ao corte etário.

Para Nascimento (2011), a identidade da educação infantil corre o risco de se fragmentar, já que uma interpretação equivocada da EC/59 pode levar a pré-escola a ser compreendida como uma antecipação da escola, fazendo com que as crianças de quatro a cinco anos percam o direito, principalmente, do brincar, previsto nas Diretrizes Curriculares Nacionais para a educação infantil (2009). Daí a importância de se proporcionar uma formação altamente qualificada aos professores no sentido de lhes garantir uma compreensão teórico-metodológica que reconheça, de maneira integrada, os cuidados e a educação da criança, tanto no trabalho com os bebês como com as crianças maiores.

Desse modo, verifica-se, por um lado, algumas contradições no âmbito das leis, por outro, alguns avanços na garantia dos direitos da criança pequena em espaços coletivos de educação, até porque "[...] seria injusto não evidenciar a importância do papel do Estado ao promover tais avanços, mesmo que seu papel fique, muitas vezes, restrito a ações emergenciais" (AZEVEDO; MASSUCATO, 2012, p. 153). Na prática, os retrocessos acontecem, justamente, pela dificuldade, em termos operacionais, de viabilizar muitas dessas conquistas no cotidiano das instituições.

Por esse motivo, enfatiza-se que a crítica à legislação não “[...] pretende enfatizar o discurso neoliberal advogando a ineficiência do Estado na garantia dos direitos sociais" (AZEVEDO; MASSUCATO, 2012, p. 153), mas apontar os inúmeros desafios colocados para um trabalho pedagógico que reconheça as especificidades desse nível de ensino.

Didonet (2001) indica três grandes objetivos que podem contribuir para a consolidação da educação infantil como questão pública: "objetivo social”, que diz respeito aos direitos das mulheres enquanto participantes da vida social, econômica, cultural e política do país; "objetivo educativo", que diz respeito à organização de um 
currículo que promova a construção de novos conhecimentos e habilidades da criança; e o "objetivo político", que está associado à formação da cidadania infantil, já que, por meio desta, a criança tem o direito de falar e de ouvir, de respeitar e ser respeitada, em suas especificidades e nas interações que vivencia com seus pares.

Assim, essas instituições são necessárias na vida da criança, pois, por meio de um atendimento de qualidade, ela tem a oportunidade de vivenciar diferentes situações de aprendizagem, trocar experiências e, ao mesmo tempo, construir sua identidade e autonomia. A qualidade dos serviços prestados diz respeito, principalmente, às ações das professoras em relação ao "[...] respeito à dignidade e aos direitos das crianças, consideradas nas suas diferenças individuais, sociais, econômicas, culturais, étnicas, religiosas etc.; direito das crianças a brincar, como forma particular de expressão, pensamento, interação e comunicação infantil” (BRASIL, 1998, v. 1, p.13).

Dessa forma, as escolas infantis têm como objetivo principal mediar o processo de construção de conhecimentos, habilidades e identidade infantil, já que tanto as professoras como as crianças têm, nessas instituições, a possibilidade de viver novas situações de aprendizagem, trocar experiências e construir suas identidades. Para isso, essas instituições devem oportunizar o trabalho coletivo, em um ambiente rico em oportunidades de desenvolvimento, e as condições necessárias para uma educação emancipatória e não alienadora.

\section{A percepção das professoras sobre a educação, o ensino e os cuidados no berçário}

Todas as participantes da pesquisa são do sexo feminino e possuem formação superior em Pedagogia. As idades variam entre vinte e quatro anos (menor idade) e cinquenta e quatro anos (maior idade). Quanto ao tempo de atuação no magistério, verificamos que somente uma professora se encontra em fase inicial de carreira, com apenas três meses de atuação na educação infantil, e as demais atuam no magistério entre três anos a dez anos.

$\mathrm{Na}$ realidade, a concepção dessas profissionais sobre o conceito de homem, sociedade e educação é que determina o tipo de atendimento oferecido, pois se verifica divergências nas respostas das participantes da pesquisa. Ao se perguntar sobre as finalidades da educação infantil na atualidade, constatou-se que, enquanto a maioria reconhece a importância dessa instituição como espaço de promoção do desenvolvimento pleno da criança, outras as identificam apenas como a disponibilização 
de um local para propiciar atividades que estimulam os aspectos cognitivos e, ainda, como espaço de preparação para a escolaridade posterior. Essa concepção de preparação relacionada à construção da língua escrita e à antecipação da escolaridade indica inconsistência na própria formação das professoras, visto que todas as participantes, como já mencionado, são pedagogas, o que pressupõe a consolidação de um arcabouço de conhecimentos sobre a organização do trabalho pedagógico com crianças desse nível de ensino.

Oliveira e Rubiano (2000) ressaltam que, embora essa etapa educacional tenha sido incluída nos textos legais, o que possibilitou a substituição da função assistencial, até então presente nas diferentes formas de atendimento, pelo caráter pedagógico, tanto a Constituição de 1988 como a LDB de 1996 apresentam, “[...] em certos momentos, uma visão de sistema educacional muito comprometida com a noção de escola e de ensino, com possíveis implicações sobre os custos do atendimento" (OLIVEIRA e RUBIANO, 2000, p. 48). Para as autoras, como parte integrante da educação básica, essas instituições constituem estatuto de unidade escolar e de modalidade de ensino, assim, conteúdos curriculares devem ser trabalhados com a criança, o que pode ser entendido por seus profissionais como escolarização e antecipação do ensino regular.

Rever esse entendimento, "superar antigos conceitos e consolidar esta etapa pertencente ao sistema educacional, enquanto, de fato atendimento educacional, por meio da socialização dos conhecimentos que hoje a fundamentam", segundo Angotti (2006, p.15), é condição para a superação do assistencialismo e, ao mesmo tempo, da visão escolarizante presente no cotidiano de muitas instituições.

De acordo com a LDB (BRASIL, 1996), em seu Art. 29, "a educação infantil, primeira etapa da Educação Básica, tem como finalidade o desenvolvimento integral da criança até cinco anos de idade, em seus aspectos físico, psicológico, intelectual e social, complementando a ação da família e da comunidade”. Essa determinação legal indica as prerrogativas da função eminentemente educacional das instituições destinadas à infância, haja vista que, além de anunciar "[...] o direito da criança ao seu desenvolvimento", também estabelece a promoção do "desenvolvimento integral da criança em suas diferentes e complementares perspectivas" (ANGOTTI, 2006, p.18).

Entretanto, para garantir o proposto em Lei, faz-se necessária uma ação integrada, advinda de outras áreas, tais como: ação social, saúde e cultura. Ressalta-se, ainda, a importância de se aceitar e entender a criança em seu estado de ser e de vir a ser, o que "exige um significado absolutamente novo para o conceito de infância, bem 
como em relação às práticas didáticas, pedagógicas, até então oferecidas", que devem ser redimensionadas, "até mesmo enquanto condição de defesa e preservação da natureza infantil” (ANGOTTI, 2006, p.19).

As escolas infantis constituem espaços importantes no cenário atual, já que complementam a educação da família, além de mediarem o processo de construção de conhecimentos, habilidades e identidade da criança. Nessa perspectiva, tanto as professoras quanto as crianças têm, nessas instituições, a possibilidade de viver novas situações de aprendizagem, trocar experiências e construir suas identidades. Nesse sentido, Dahlberg, Moss e Pence (2004, p.72) ressaltam que a criança, embora tenha uma capacidade diferente da dos adultos, "[...] é entendida e reconhecida como sendo parte da sociedade" e "não existe apenas no lar da família, mas também no mundo mais amplo".

Assim, quem trabalha com a criança deve ter clareza quanto às concepções de infância e de criança, defendidas nos dias atuais, bem como da finalidade da educação infantil hoje, para que possa, desse modo, proporcionar às crianças e suas famílias uma educação infantil de qualidade, adequada à ideia de criança cidadã e aos direitos dessa parte da população, como estabelece a legislação brasileira.

Angotti (2006, p. 19) destaca, também, que a profissionalidade das professoras “deverá estar fundamentada na efetivação de um cuidar que promova educação, e de uma educação que não deixe de cuidar da criança, de atendê-la em suas necessidades e exigências essenciais desde a sua mais tenra idade em atividades, espaços e tempos de ludicidade". Assim, as profissionais devem ser capazes de atender a criança, de modo a prover e promover seu processo de desenvolvimento, por meio da implementação dos princípios estabelecidos pelas Diretrizes Curriculares Nacionais para a educação infantil (BRASIL, 2009). Conforme Angotti (2006, p. 25):

\begin{abstract}
A educação infantil fundamenta-se na necessidade de se entender a criança de corpo inteiro, de não fragmentá-la em suas perspectivas e, sobretudo, no que concerne à insustentável dissociação entre sua razão e emoção, de compreendê-la e trabalhá-la na sua inteireza, integrando práticas educativas baseadas em ideário pedagógico que possa desenvolver seu potencial de elaboração e expressão comunicativa.
\end{abstract}

Quando se pergunta a opinião das professoras sobre a possibilidade de ensinar crianças pequenas, para além dos cuidados de higiene, alimentação e segurança física, verifica-se que todas acreditam que é possível ensinar no berçário, por meio de música, histórias, brincadeiras com movimentos corporais, espelhos e móbiles, tais como: 
figuras de animais, cores, macarrão e gelatina na bacia. Apesar da unanimidade nas respostas, identifica-se uma dicotomia nos discursos das professoras, haja vista que o ensino, segundo a percepção das mesmas, se volta apenas para as atividades orientadas. Outra questão que chamou a atenção foi a concepção equivocada sobre o ensinar crianças pequenas, considerando-se que, situações como guardar brinquedos, ensinar regras, aguardar em fila e esperar a vez em que se manifestar, apareceram como indicadores do trabalho de ensinar desenvolvido com os pequenos.

A esse respeito, pode-se pensar que o trabalho no berçário acaba se reduzindo a um ativismo pedagógico, pois as atividades que fazem parte da rotina escolar acabam sendo incorporadas ao currículo como conteúdo, como conhecimento para a primeira infância. Essa lógica de aprendizagem é muito usual nos espaços educativos voltados à primeira infância, assim, o ativismo supera o conteúdo e o ensino, tornando-se prática pela prática. Pode-se dizer que há uma busca sem limites por "fazeres" e não por "saberes", principalmente por parte das professoras, que ficam vislumbradas pelo mundo do receituário educativo. Essa prática é tão naturalizada no campo da educação que se transformou no grande lema educacional, que se traduz em saber fazer.

Essa proposta ativista acaba sendo mal conduzida nos espaços formativos, principalmente quando confundida com a manipulação motora de objetos e materiais ou com a produção de atividades manuais, por exemplo. A escola que trabalha sob essa perspectiva não compreende como se processa o conhecimento na criança, pois o pensamento da criança, como do adulto, enquanto ação mental (representação), é tão ativo quanto qualquer movimento manifesto.

Arce e Silva (2009), em um estudo que investigou se é possível ensinar no berçário, defendem o ensino como eixo articulador do trabalho com crianças menores de três anos. É comum se ouvir, em meios escolares e não escolares, que as necessidades básicas dos bebês, como trocar fraldas e alimentar, são mais importantes nessa fase. Tais ações constituem simples atos de cuidado. No entanto, é fundamental compreender que a criança aprende para se desenvolver em seus múltiplos aspectos de vida: social, afetivo, físico, dentre outros, o que subentende a necessidade de um trabalho pedagógico em que o ensino é o eixo articulador e o professor é reconhecido como mediador do processo, no sentido de possibilitar provocações que gerem mudanças no desenvolvimento infantil.

Este estudo, entretanto, não tem a pretensão de defender práticas pedagógicas que não consideram as especificidades das crianças pequenas e buscam educá-las como 
se fossem maiores. Um outro equívoco é acreditar que a educação da criança pequena pode ser pensada em um segundo momento, quando estiverem maiores, pois assim se ganha espaço, nessa fase, para apenas cuidar, desconsiderando que a criança cria potencialidades e se desenvolve desde que nasce, mediante as aprendizagens.

O cuidado é muito importante nessa fase, pois o bebê, desde o nascimento, depende do adulto para a sobrevivência. Por outro lado, a criança nasce com reflexos involuntários, e a formação dos reflexos voluntários depende dos estímulos externos oferecidos, pois estes são imprescindíveis e devem começar já no primeiro mês de vida, quando a função psicológica da percepção começa a se desenvolver. Ao se observar o reflexo condicionado da amamentação, percebe-se que o bebê, gradativamente, aperfeiçoa o ato de mamar. Após o aparecimento dos reflexos condicionados, nos primeiros meses de vida, é necessário um olhar atento do educador para outras necessidades próprias dessa fase, que interferem no desenvolvimento adequado da criança e dizem respeito: ao aparato visual, às modificações na atividade motora (enrugar a testa, girar o olhar em uma direção, etc.) e à sensibilidade auditiva, tátil e olfativa.

No primeiro ano de vida, a criança, graças aos estímulos oferecidos, sente necessidade de apalpar objetos, o que desenvolve a atenção, ou seja, o olhar atento, mesmo que este dure poucos minutos, o que é normal, pois essa função se aperfeiçoa gradativamente. Assim, se há um trabalho voltado para essa característica, a criança aprende e educa a si mesma. É essencial ressaltar que a linguagem é um aspecto importante do desenvolvimento, e é na interação com a professora que a criança se apropria de palavras, assim, ao final de um ano de vida, ela já pode ter internalizado um universo vocabular de dez a vinte palavras.

Diante do que foi respondido pelas entrevistadas, em relação ao ensino das crianças pequenas, percebe-se que, em seus discursos, o ato de cuidar ainda está bem presente, o que evidencia o caráter espontâneo, e não programado, do trabalho desenvolvido. Segundo Silva (2009), esse tipo de prática precisa ser superada, pois, como o ensino é o eixo articulador do trabalho com bebês, a questão do educar e do cuidar devem se integrar nesse eixo, uma vez que se relaciona à transmissão da cultura aos pequenos, assim, a estimulação deverá ser uma das atividades principais do trabalho educativo no sentido de apresentar o mundo externo a eles.

Cabe à professora investir em conhecimentos teóricos e práticos, a fim de propiciar mudanças na vida da criança. O conhecimento teórico, na atividade dessa 
profissional, conforme Mello (2007), é a condição máxima de sua liberdade, liberdade no sentido de fazer escolhas acertadas em relação a um trabalho educativo intencional que supra as necessidades de aprendizagem social da criança.

Em relação aos conteúdos de ensino em creches, Martins (2009) aponta que a escola deve ensinar para além do que a criança vivencia em seu cotidiano, pois, se a escola desenvolve apenas ações espontâneas, cumpre o mesmo papel exercido por outras instituições sociais. No entanto, enquanto responsável pela socialização do saber elaborado, a escola deve cumprir a tarefa de ensinar, mas é importante que a professora se aproprie de diversos saberes interdisciplinares, tais como: pedagógicos, sociológicos, psicológicos e de saúde, para que tenha condição de interferir, de modo direto e indireto, na educação da criança. Esses conhecimentos, entretanto, devem ser apresentados de forma indireta, traduzidos na ação e não em forma conceitual, pois, nessa faixa etária, a criança está começando a conhecer e a dar significado às coisas. Desse modo, nos momentos de interação com o outro e com os objetos, no trabalho direto e indireto da professora, a criança vai explorando e desenvolvendo sua percepção das coisas e a capacidade de se relacionar com a realidade vivida.

Sobre a questão da qualidade do atendimento oferecido no berçário e sobre a possibilidade de articulação entre a rotina de cuidados e educação no fazer diário, as professoras apontaram a rigidez, tanto da rotina quanto do horário, entre uma atividade e outra, como fator que compromete e/ou impossibilita um trabalho pedagógico que promova o desenvolvimento pleno dos bebês. Outra questão destacada foi a dificuldade na organização do espaço, em função da própria estrutura física inadequada da instituição. Para além desses percalços no cotidiano, as educadoras acreditam que é possível propiciar situações de aprendizagem e de desenvolvimento da linguagem das crianças.

Pasqualini e Martins (2008, p. 78) afirmam que os cuidados e a educação constituem elos mais que significativos e, portanto, inseparáveis, uma vez que "[...] é impossível cuidar de crianças sem educá-las", considerando-se que a dicotomia entre essas dimensões se faz somente quando a superficialidade se torna parte da ação de quem lida com as crianças. Assim, “[...] o cuidado está presente em alguma medida em todos os níveis de ensino e em toda relação educativa, não constituindo uma dimensão exclusiva ou específica da educação infantil” (PASQUALINI; MARTINS, 2008, p. 79).

A criança, desde que nasce, interage com as pessoas e aprende com elas, atribuindo significados ao que a cerca, pois “[...] esse processo que faz com que a 
criança passe a participar de uma experiência cultural que é própria de seu grupo social é o que chamamos de educação" (BUJES, 2001, p. 16). Por outro lado, esse evento não ocorre de maneira isolada, fora de um ambiente de cuidados, de uma experiência afetiva e de um contexto social que ampara a criança, segundo Bujes (2001).

Quando se questionou sobre a participação das famílias no cotidiano da instituição, observou-se uma insatisfação geral nas respostas, pois as professoras ressaltaram que, embora estabeleçam um bom diálogo com os pais, nem sempre é possível realizar um trabalho conjunto, principalmente no que diz respeito às rotinas que envolvem eventos relacionados ao controle dos esfíncteres e da retirada da fralda e da chupeta. As famílias, segundo as participantes, delegam essas responsabilidades somente às professoras.

Nesse sentido, vale reiterar que:

A creche não substitui a educação familiar. Ela a complementa. Assim, nem tudo pode ficar sob a responsabilidade das instituições de educação infantil. Por isso fica clara a importância de um bom relacionamento entre a família e essas instituições. [...] Nessa relação, conflitos podem surgir. Se bem conduzidos, podem resultar num processo de melhoria na qualidade do serviço prestado pela instituição e no desenvolvimento da família como um todo (SILVA, 2000, p.186).

As Diretrizes Curriculares Nacionais para a Educação Infantil (2009), no Art.7º, inciso II, estabelecem que as instituições de educação infantil devem cumprir sua função sociopolítica e pedagógica, "assumindo a responsabilidade de compartilhar e complementar a educação e cuidado das crianças com as famílias." Assim, como proposto no Art.8, Parágrafo 1, Inciso III, deve haver "a participação, o diálogo e a escuta cotidiana das famílias, o respeito e a valorização de suas formas de organização". Sobre essa questão, o Estatuto da Criança e do Adolescente (1990) assegura, em seu artigo 53, aos pais ou responsáveis, o direito de ter ciência do processo pedagógico, bem como de participar da definição das propostas educacionais.

Outra questão indicada nas respostas refere-se ao pouco envolvimento dos pais nas atividades consideradas, pelas professoras, como pedagógicas, pois ficou claro, na perspectiva destas, a falta de interesse dos mesmos por ações que envolvem a aprendizagem dos bebês. A preocupação maior gira em torno da segurança física, da alimentação e do sono da criança. As professoras, em consequência disso, sentem-se 
desprestigiadas, pois acreditam que as famílias não as percebem como profissionais da educação infantil, mas como alguém que somente cuida das crianças.

Infelizmente, por uma questão histórica e cultural, em especial nas instituições públicas ou filantrópicas, os pais não exercem, de fato, o direito de conhecer e participar do trabalho pedagógico. O que se observa, frequentemente, são pais ou responsáveis que reclamam apenas o direito a uma vaga nesse nível de ensino, ou então, que se queixam das normas e rotinas estabelecidas pela instituição. Por outro lado, as professoras encontram dificuldades em se reconhecer como professoras de berçário, uma vez que está arraigada a dicotomia entre o cuidar e o educar, bem como a ideia equivocada de que, para os bebês, basta suprir suas necessidades físicas.

Para superar as dificuldades vividas na relação entre escola e família, as instituições poderão compartilhar a ação educativa por meio de atividades que permitam às professoras: conhecer a criança; estabelecer critérios educativos comuns; oferecer aos pais exemplos de intervenção e de interação com as crianças; ajudá-los a conhecer a função educativa do trabalho; captar o interesses dos mesmos; e conhecer seus anseios, críticas e valores.

Para Bassedas, Huguet e Solé (1999, p.26), nas relações entre a instituição de educação infantil e as famílias:

O conhecimento mútuo e o estabelecimento de acordos entre o contexto familiar e o escolar atuam em beneficio da criança pequena e promovem o seu bem-estar. As relações entre a família e a escola somente podem ser construtivas se estiver baseada no respeito mútuo, na confiança e na aceitação das peculiaridades de cada um.

Ao se defender uma relação de 'trocas' entre a família e a escola, é importante que se considere que, para o desenvolvimento de ambos, ou seja, pais e professores, tal relação deve ser:

[...] um exercício de aceitação das diferenças. Os pais aprendem a exercer seu direito de participar do atendimento dado aos filhos, ao mesmo tempo em que se aprendem a compreender o ponto de vista dos profissionais da educação infantil. Por outro lado, os profissionais aprendem seu dever de respeitar a cultura e o saber das famílias (MELLO, 2000, p.25).

Em resumo, na instituição de educação infantil, não é possível falar de criança e de trabalho pedagógico sem incluir a família, já que as ações desenvolvidas pelas 
professoras devem ser partilhadas com os pais e, ao mesmo tempo, planejadas e avaliadas constantemente, de modo a garantir o desenvolvimento integral dos bebês.

\section{Considerações Finais}

A preocupação, nesse estudo, foi conhecer as percepções das professoras sobre o trabalho pedagógico desenvolvido no berçário, sobretudo no que tange aos aspectos que envolvem a rotina dos cuidados e da educação dos pequenos em espaços coletivos. $\mathrm{O}$ intuito foi ressignificar o ensino como eixo articulador do trabalho com bebês, já que o objetivo principal da educação infantil é promover uma educação de qualidade para todas as crianças desde a mais tenra idade. Por meio das respostas das participantes, verificou-se que as mesmas reconhecem a importância dessa etapa educativa na vida das crianças, no entanto identificou-se, também, uma dicotomia nos discursos, que ora enfatizam o caráter assistencial do trabalho com os bebês, ora o ativismo pedagógico, em detrimento de uma educação capaz de cuidar, educar e ensinar os pequenos em um ambiente altamente qualificado.

Diante disso, compreender como se processa o trabalho pedagógico na educação de crianças pequenas tornou-se um desafio para esta pesquisa, uma vez que algumas questões respondidas pelas professoras suscitaram novos direcionamentos para se pensar o processo formativo das mesmas, pois a superação dessas práticas só será possível se as professoras buscarem a capacitação constante em serviço, e a avaliação da própria prática desenvolvida no berçário. Dessa maneira, a formação continuada deverá contribuir para a superação de ações assistencialistas ou ativistas em favor do conhecimento das características e necessidades dos bebês, já que educá-los exige esforço e comprometimento, por meio um trabalho que assegure a integração entre os cuidados e a educação na rotina da educação infantil.

A parceria entre as escolas infantis e as famílias, nesse processo, se faz urgente e necessária, pois, a partir das queixas das professoras, expressas em suas respostas, foi possível verificar a impossibilidade de se realizar um trabalho conjunto. Por esse motivo, considera-se que cabe à direção, à coordenação e às professoras buscar estratégias para a conscientização dos pais ou responsáveis sobre a importância da relação saudável entre ambas as instituições - escola infantil e família, visando sempre ao desenvolvimento cognitivo e ao bem estar físico, emocional e social da criança. Ora, 
a escola infantil deve se comprometer com o desenvolvimento integral dos bebês, oferecendo-lhes um trabalho pedagógico que respeite suas necessidades e promova o desenvolvimento das diferentes linguagens.

\section{REFERÊNCIAS}

ANGOTI, M. (Org.), Educação infantil: Para quê, Para quem e Por quê? Campinas: editora Alínea, 2006.

ARCE, A.; SILVA, J. C. É possível ensinar no Berçario? O ensino como eixo articulador do trabalho com bebês ( 6 meses a 1 ano de idade. In: ARCE, Alessandra;

AZEVEDO, Heloisa H. Oliveira de; MASSUCATO, Jaqueline C. Identidade da educação infantil e de seus professores: perspectivas de reconstrução. Revista de Educação PUC-Campinas, Campinas, 17 (2) :151-161, jul./dez., 2012.

BASSEDAS, E; HUGUET, T; SOLÉ, I. Aprender e ensinar na educação infantil. Porto Alegre: ARTMED, 1999.

BRASIL. Constituição da República Federativa do Brasil. Brasília, DF: Senado Federal, 1988, 305 p.

Estatuto da Criança e do Adolescente. Lei no 8.069, de 13 de junho de 1990.

. Ministério da Educação e Cultura. Lei de Diretrizes e Bases da Educação

Nacional. Lei $\mathrm{n}^{\circ}$ 9394, de 20 de dezembro de 1996. Dispõe sobre as Diretrizes e Bases da Educação Nacional. Brasília, DF: MEC, 1996.

Ministério da Educação e do Desporto. Secretaria de Educação Básica. Política nacional de educação infantil. Brasília, DF: MEC/SEB, 2006.

Parecer CNE/CEB 020/2009; Resolução CNE/CEB N. 5/2009. Diretrizes Curriculares Nacionais para a Educação Infantil. Brasília, DF: Conselho Nacional de Educação/Câmara da Educação Básica, 2009.

Lei ${ }^{\circ} 12.796$ de 04 de abril de 2013. Altera a Lei $n^{\circ} 9.394$ de 20 de dezembro de 1996-LDB. Brasília: 2013.

BUJES, Maria Isabel E. Escola infantil: pra que te quero? In: CRAIDY, Carmem; KAERCHER, Gládis E. (Org). Educação Infantil: pra que te quero? Porto Alegre: Artmed Editora, 2001. p.13-23.

DAHLBERG, Gunilla. MOSS Peter. PENCE, Alan. Qualidade na educação da primeira infância: perspectivas pós-modernas. trad. Magda França Lopes. Porto Alegre: Artmed, 2004.

DIDONET, Vital. Creche: a que veio, para onde vai. In: Educação Infantil: a creche, um bom começo. Em Aberto/Instituto Nacional de Estudos e Pesquisas Educacionais. v 18, n. 73. Brasília, 2001. p.11-28. 
KRAMER, Sonia. A política do pré-escolar no Brasil: a arte do disfarce. 5. ed. São Paulo: Cortez, 1995.

KRAMER, Sonia. S. Propostas pedagógicas ou curriculares de educação infantil: para retomar o debate. Pro-Posições, v.13, n.38, p.65-82, maio/ago. 2002.

LEONTIEV, A . Os princípios psicológicos da brincadeira escolar. In: VYGOTSKY, L. S. et al. Linguagem, desenvolvimento e aprendizagem. Tradução por Maria da Penha Villa Lobos. São Paulo: Ícone/Edusp, 1988. p. 127-144.

MARTINS, Lígia Marcia. O Ensino e o Desenvolvimento da Criança de zero a três anos. In: ARCE, Alessandra; MARTINS, Lígia Marcia (Orgs). Ensinando aos pequenos de zero a três anos.Campinas, SP: Editora Alínea, 2009. p. 93-122.

MELLO, Sueli. Amaral. As práticas educativas e as conquistas das crianças pequenas. In: RODRIGUES, E.; ROSIN, S. M (orgs). Infância e Práticas Educativas. Maringá: Eduem, 2007.

MELLO. Sueli, Amaral. Linguagem, consciência e alienação: o óbvio como obstáculo ao desenvolvimento da consciência crítica. Marília: Unesp-Marília- Publicações, 2000.

NASCIMENTO. Maria L. Algumas considerações sobre a infância e as políticas de educação infantil. Educação \& Linguagem • v. 14 • n. 23/24, 146-159, jan.-dez. 2011.

OLIVEIRA; Zilma de Moraes Ramos; RUBIANO, Márcia R. Bonanganba. Um estudo das perspectivas para a educação infantil a partir da nova LDB. In: MACHADO, Maria Lucia de A. (org.). Educação infantil em tempos de LDB. São Paulo: FCC/DPE, 2000.

PÁDUA, Elizabete. M. M. de. Metodologia da pesquisa: abordagem teórico-prática. $10^{\circ}$ ed. Campinas, São Paulo: Papirus, 2004.

PASQUALINI, Juliana C.; MARTINS, Lígia M. A Educação Infantil em busca de identidade: análise crítica do binômio "cuidar-educar" e da perspectiva anti-escolar em Educação Infantil. Psic. da Ed., São Paulo, 27, $2^{\circ}$ sem. de 2008.

SILVA, Tomaz Tadeu da. Teoria cultural e educação: um vocabulário crítico. Belo Horizonte: Autêntica, 2000 (Coleção Estudos Culturais, vol. 4)

VYGOTSKY. L. S. Obras escogidas. v. 4, Madrid:Visor, 1997.

\section{Como referenciar este artigo}

PASCHOAL, Jaqueline Delgado et al. A educação infantil em foco: desafios e perspectivas para a educação dos bebês. Revista Ibero-Americana de Estudos em Educação, Araraquara, v. 11, n. 4, p. 2174-2190, 2016. Disponível em: <http://dx.doi.org/10.21723/riaee.v11.n4.8530>. E-ISSN: 1982-5587.

Submetido em: abril/2016

Aprovação final em: outubro/2016 